\title{
Apendicitis aguda atípica diagnosticada durante una colonoscopia
}

\section{Colonoscopic diagnosis of acute appendicitis with atypical presentation}

\author{
M. Ostiz ${ }^{1}$, E. Amorena1, A. Campillo', R. Bermejo ${ }^{2}$, F. Escolar ${ }^{3}$
}

\section{Sr. Director:}

La apendicitis aguda es una de las causas más comunes de abdomen agudo en nuestro medio. Sin embargo, el diagnóstico endoscópico de esta patología es muy poco frecuente, y en general los pocos casos descritos corresponden a presentaciones atípicas de esta entidad en las cuales la clínica o las pruebas de imagen no fueron concluyentes ${ }^{1}$.

Varón de 18 años sin antecedentes médicos de interés que acudió al Servicio de Urgencias por un cuadro de dolor abdominal fluctuante en mesogastrio de una semana de evolución, acompañado de diarrea, realizando unas 2 deposiciones al día de consistencia blanda o líquida sin productos patológicos. El dolor se había intensificado en el día previo, localizándose de forma difusa a nivel de fosa ilíaca derecha. Coincidiendo con el momento de mayor intensidad el paciente presentó un único vómito de contenido alimentario.

A la exploración física estaba afebril, y con buen estado general. Presentaba dolor selectivo a la palpación en fosa ilíaca derecha (FID), sin signos de irritación peritoneal. Se le realizó analítica que mostraba leucocitosis (16.000) con neutrofilia (82\%), y elevación de reactantes de fase aguda, con fibrinógeno de 501 (N: 200-400) y proteína $\mathrm{C}$ reactiva de 26 (N: 1-10). Se solicitó ecografía abdominal urgente, donde se objetivó líquido libre a nivel de FID y un mínimo engrosamiento de la pared de íleon terminal. El apéndice fue visualizado parcialmente, y presentaba un aspecto ecográfico normal.

Con un diagnóstico provisional de ileitis terminal el paciente ingresó en hospitalización, donde permaneció 48 horas, evolucionando favorablemente, permaneciendo afebril, con desaparición completa del dolor abdominal y normalización de las alteraciones analíticas previas.

Fue dado de alta, realizándose colonoscopia programada 4 días después. La endoscopia mostró un íleon terminal de aspecto normal (posteriormente las biopsias también confirmaron la ausencia de alteración a este nivel), sin embargo se objetivó inflamación llamativa de la mucosa periapendicular, que estaba edematosa y congestiva, y protruía hacia el ciego (Fig. 1).
1. Aparato Digestivo. Hospital Reina Sofía. Tudela. Navarra. España.

2. Radiología. Hospital Reina Sofía. Tudela. Navarra. España.

3. Medicina Interna. Hospital Reina Sofía. Tudela. Navarra. España.

Recepción: 26 de diciembre de 2012

Aceptación definitiva: 16 de enero de 2013
Correspondencia:

Miriam Ostiz LLanos

Aparato Digestivo

Hospital Reina Sofía

Carretera Tarazona Km. 3

31500 Tudela. Navarra. España

E-mail: miriam.ostiz@gmail.com 


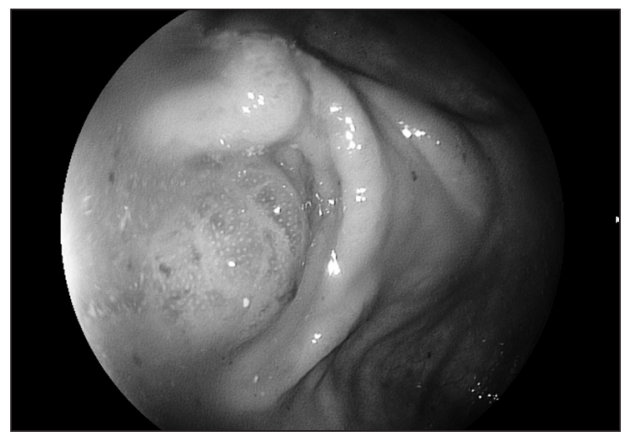

Figura 1. Mucosa periapendicular inflamadada y congestiva, que protruye hacia la luz del ciego.

Ante estos hallazgos se solicitó un TC abdominal para completar el estudio, donde se visualizó un apéndice engrosado de $1,63 \mathrm{~cm}$ de diámetro, con signos inflamatorios en grasa adyacente, adenopatías locales y una pequeña cantidad de líquido libre en pelvis. Ileon terminal de aspecto normal (Fig. 2).

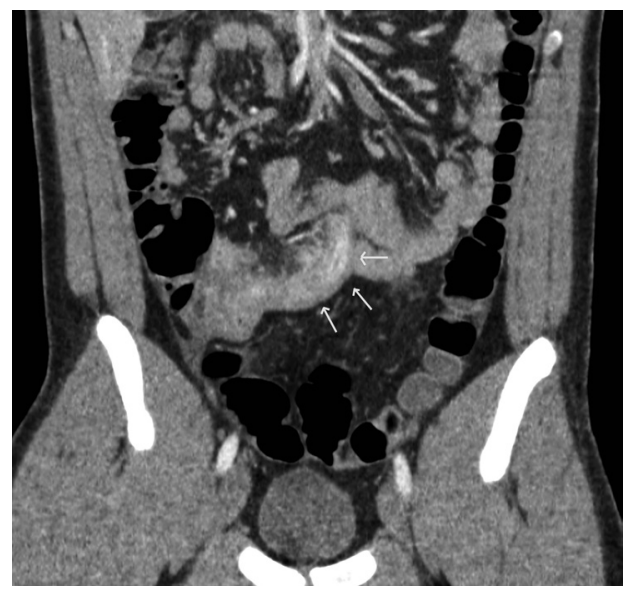

Figura 2. Corte coronal del abdomen en el que se observa un apéndice inflamado y engrosado (flechas), con afectación de la grasa adyacente.

Tras comentarse el caso con el Servicio de Cirugía General se decidió tratamiento antibiótico y apendicectomía programada, que se realizó dos meses después sin incidencias.
La apendicitis aguda es una inflamación del apéndice vermiforme. Se cree que puede producirse a raíz de una obstrucción en su luz, que a su vez puede deberse a diversas causas como fecalitos, hiperplasia folicular linfoide, y más raramente por cuerpos extraños, bridas fibrosas, infecciones parasitarias y tumores en la zona (carcinoides, mucocele o adenocarcinoma) ${ }^{2}$. Existen también casos de apendicitis agudas no obstructiva, cuya etiología ha sido atribuida a infecciones entéricas bacterianas o víricas. Aunque puede presentarse a cualquier edad la incidencia es mayor en la segunda y tercera década de la vida, con prevalencia del sexo masculino $(1,4: 1)^{3}$.

Los síntomas típicos incluyen dolor a nivel de fosa ilíaca derecha, con náuseas o vómitos acompañantes y febrícula. La presencia de fiebre elevada suele asociarse a apendicitis perforada o gangrenosa. Existen presentaciones atípicas manifestadas con síntomas dispépticos, flatulencia, diarrea (como en el caso que aquí se presenta), y anorexia ${ }^{4}$.

Aproximadamente la mitad de las apendicitis agudas pueden diagnosticarse con datos clínicos y analíticos, sin embargo, existen grupos de pacientes en los que son más frecuentes las presentaciones atípicas como es el caso de los lactantes y niños menores de 3 años, ancianos, gestantes, apéndice de localización retrocecal, pacientes inmunosuprimidos, o con ciertas comorbilidades como obesidad o diabetes.

Cuando el diagnóstico clínico no es evidente se pueden utilizar estudios complementarios de imagen como la ecografía o el TC abdominal, con una sensibilidad para la apendicitis aguda del $76 \%$ y $97 \%$ respectivamente y una especificidad del $90 \%$ y $100 \%$ respectivamente ${ }^{5}$.

La colonoscopia convencional no está indicada en el protocolo diagnóstico de la apendicitis aguda, es más, la exploración podría complicar el proceso condicionando un empeoramiento del dolor, una hemorragia digestiva o una perforación ${ }^{1}$. De hecho, aunque es algo excepcional, se han descrito algunos casos de apendicitis aguda en personas previamente sanas tras 
realización de una colonoscopia ${ }^{6}$, probablemente secundarios a una introducción de material fecal en la luz del apéndice al insuflar aire en el ciego ${ }^{7}$.

Por todo ello no es frecuente hacer un diagnóstico de esta entidad mediante colonoscopia, y de hecho en la mayoría de libros y atlas de endoscopia hay poca (o nula) mención de la patología apendicu$\operatorname{lar}^{8}$.

En general, podríamos decir que los pocos casos descritos de apendicitis diagnosticados durante esta exploración corresponden a pacientes con presentaciones atípicas, en los cuales los estudios previos no habían sido concluyentes para apendicitis aguda o se sospechaban otras patologías, como en el caso de nuestro paciente, en el cual la presencia de diarrea como uno de los síntomas principales, junto con la falta de diagnóstico ecográfico y la rápida resolución de las alteraciones clínicas y analíticas nos hicieron descartar el diagnóstico de apendicitis, orientando el caso hacia una posible ileitis terminal.

Por otro lado, algunos autores postulan el papel de la colonoscopia en el tratamiento de la apendicitis aguda, ya que se han descrito varios casos de drenaje endoscópico del material purulento mediante inserción de un catéter a través del orificio apendicular ${ }^{1,9-11}$, lo que permite realizar una apendicectomía programada meses después del proceso agudo o incluso evitar la cirugía en algunos casos.

También se han descrito casos de extracción endoscópica de fecalitos impactados en el orificio apendicular ${ }^{12}$ e incluso de cierre endoscópico de fístulas producidas tras una cirugía de apendicitis perforada ${ }^{13}$.

De cualquier manera hay muy pocos casos publicados sobre estas técnicas, y hoy por hoy la colonoscopia no tiene un papel establecido en el diagnóstico y tratamiento de la apendicitis aguda por lo que no está indicada su realización de forma rutinaria. Es por ello que imágenes como la que aquí mostramos siguen siendo a día de hoy un hallazgo poco común.

\section{BIBLIOGRAFÍA}

1. Chang HS, Yang SK, Myung SJ, Jung HY, Hong WS, KIM JH ET AL. The role of colonoscopy in the diagnosis of apendicitis in patients with atypical presentations. Gastrointest Endosc 2002; 56: 343-348.

2. ARnBJörnsson E, Bengmark S. Obstruction of the appendix lumen in relation to pathogenesis of acute apendicitis. Acta Chir Scand 1983; 149: 789-791.

3. JAFFE BM, BERger DH. The Appendix. In: Schwartz Principles of Surgery, 8th ed, Schwartz SI, Brunicardi CF (Eds). Mc GrawHill Health Pub. Division, New York 2005.

4. George A, Sarosi JR, Richard H. Apendicitis. En SLEISENGER MH, Fortrand JS, EDITORES. Enfermedades Digestivas y Hepáticas. $8^{a}$ Edición. Madrid: Elsevier; 2008: 2600-2609.

5. Horton MD, Counter SF, Florence MG, Hart MJ. A prospective trial of computed tomography and ultrasonography for diagnosing apendicitis in the atypical patient. Am J Surg 2000; 179: 379-381.

6. Aguilar-Shea Al,Gallardo C, Aranda J. Apendicitis aguda tras colonoscopia. Med Clin 2011; 137: 710.

7. Petro M, Minchoa A. Asymptomatic early acute apendicitis initiated and diagnosed during colonoscopy. A case report. Wold J Gastroenterol 2005; 11: 5398-5400.

8. KHAWAJA FI. Diseases of the appendix recognized during colonoscopy. Saudi J Gastroenterol 2002; 8: 43-52.

9. SAid M, Ledochowski M, Dietze O, Simander H. Colonoscopic diagnosis and treatment of acute apendicitis. Eur J Gastroenterol Hepatol 1995; 7: 569-571.

10. Ohtaka M, Asakawa A, Kashiwagi A, Fujino Ma, Kasal H, Matsumoto Y. Pericecal appendiceal abscess with drainage during colonoscopy. Gastrointest Endosc 1999; 49: 107-109.

11. Liu CH, Tsai FC, Hsu SJ, Yang PM. Succesful colonoscopic drainage of appendiceal pus in acute apendicitis. Gastrointest Endosc 2006; 64: 1011-1012.

12. Nadler LH, Tangen LE. Colonoscopic disimpaction of the apendiceal orifice. Gastrointest Endosc 1991; 37: 500-501.

13. Lee SO, Jeong YJ. Colonoscopic clipping of fecal fistula that ocurred as a post operative complication in patients with perforated apendicitis. Two case reports. Gastrointest Endosc 2001; 54: 245-247. 